\title{
Application of Artificial Neural Networks for Emission Modelling of Biodiesels for a C.I Engine under Varying Operating Conditions
}

\author{
R.Manjunatha \\ Assistant Executive Engineer, Irrigation Department, GBC Division Guntakal, A.P, India \\ Tel: 91-94-4052-2877Ｅ-mail: manju.biods1@gmail.com \\ P. Badari Narayana \\ Assistant Professor, Department of Mechanical Engineering \\ Sreenidhi Institute of Science and Technology (SNIST), Hyderabad, A.P, India \\ Tel: 91-94-4188-9441Ｅ-mail:badari.p@gmail.com \\ K. Hema Chandra Reddy \\ JNTU College of Engineering, JNTUA, Pulivendula, A.P, India \\ E-mail: hemchand@rediffmail.com
}

\begin{abstract}
The technical analysis conducted in this study deals with the modelling of diesel engine exhaust emissions using artificial neural networks. Objective of this study is to understand the effectiveness of various biodiesel fuel properties and engine operating conditions on diesel engine combustion towards the formation of exhaust emissions. The experimental investigations have been carried out on a single cylinder Direct Injection (DI) combustion ignition (CI) engine using blends of biodiesel methyl esters from Pongamia, Jatropha and Neem oils. The performance parameters such as brake power (BP), brake thermal efficiency (BTE), brake specific fuel consumption (BSFC), volumetric efficiency, exhaust gas temperature (EGT) were measured along with regulated and unregulated exhaust emissions of $\mathrm{CO}, \mathrm{HC}$ and $\mathrm{NO}_{\mathrm{x}}$. An Artificial neural network (ANN) was developed based on the available experimental data. Multi layer perceptron neural network was used for nonlinear mapping between input and output parameters of ANN. Biodiesel blend percentage, calorific value, density, Cetane number of each biodiesel blend and operating load were used as inputs to train the neural network. The exhaust gas emissions - $\mathrm{NO}_{\mathrm{x}}, \mathrm{CO}$ and $\mathrm{HC}$ are predicted for the new fuel and its blends. Different activation functions and several rules were used to train and validate the normalized data pattern and an acceptable percentage error was achieved by Levenberg-Marquardt design optimization algorithm. The results showed that training through back propagation was sufficient enough in predicting the engine emissions. It was found that $\mathrm{R}$ (Regression Coefficient) values were $0.99,0.95$ and 0.99 for $\mathrm{NO}_{\mathrm{x}}, \mathrm{CO}$ and $\mathrm{HC}$ emissions, respectively. Therefore, the developed model can be used as a diagnostic tool for estimating the emissions of biodiesels and their blends under varying operating conditions.
\end{abstract}

Keywords: Artificial neural network, Biodiesel, Engine Performance, Exhaust Emissions

\section{Introduction}

Biodiesel is favorably viewed as a potential green alternative fuel and can improve the economic growth of the country in the form of employment in regional \& rural areas. Biodiesel fuel refers to a non-petroleum-based fuel consisting of short chain alkyl (methyl or ethyl) esters, typically made by transesterification of vegetable oils or animal fats, which can be used (alone, or blended with conventional petroleum diesel) in unmodified diesel-engine vehicles. Though there are some positive environmental impacts of the use of biodiesels in diesel engines, there is a need to analyze their exhaust emissions for the benefit of human health and other environmental concerns. Making and burning of biodiesel inside the diesel engines as fuel, contributes to atmospheric carbon dioxide, sulphur dioxide, $\mathrm{NO}_{\mathrm{x}}$, smoke and particulate matter emissions to a smaller extent than burning the conventional diesel. The estimation of biodiesel emissions is a non-linear complex problem due to variations in chemical and thermodynamic properties of biodiesels that affect the combustion process. Many researchers have carried out experiments to evaluate diesel engine exhaust emissions for various biodiesel blends. Carrying out the experiments which involve the measurement of emissions of 
the diesel engine is laborious and costly. This research work analyses and models the experimental data of three different biodiesels and their blends (up to B100) operated at varying operating conditions. In this work, an artificial neural network based computing model is developed to estimate diesel engine exhaust emissions by training the ANN with available experimental data. The developed model was able to predict the exhaust emissions for a new third biodiesel fuel and its blends with suitable accuracy.

\section{Biodiesel definition}

Biodiesel is defined as the mono alkyl esters of long chain fatty acids derived from vegetable oils or animal fats, for use in diesel engines. Biodiesels are called $\mathrm{CO}_{2}$ neutral as carbon in biofuels was recently extracted from atmospheric carbon dioxide by growing plants. Biodiesel consists of alkyl esters of fatty acids produced by transesterification of vegetable oils. The structure of a typical biodiesel molecule consisting of alkyl group as shown in the Fig. 1

\section{Fig.1. Structure of alkyl group methyl ester}

Biodiesels are produced through a chemical process known as transesterification in which an ester is reacted with alcohol to produce another ester and long chain hydrocarbons known as fatty acids. This process also reduces the viscosity of oil and produces glycerin along with mono alkyl esters.

\section{Influencing Fuel Properties for analyzing exhaust emissions:}

Biodiesels are characterized by properties such as density, flash point, fire point, carbon residue, sulphur content, cetane number and calorific value of the fuel. Density, Calorific value and cetane number are determined in laboratory for various biodiesel blends of Pongamia Methyl ester, Neem Oil Methyl Ester and Jatropha Methyl Ester. The effect of fuel properties on exhaust emissions is analyzed in this work. Density of biodiesel is an important factor for modelling emissions as it increases with biodiesel percentage. Thermal efficiency of a diesel engine is improved with higher calorific value of the fuel and facilitates better combustion resulting in high temperatures inside the cylinder. This results in higher $\mathrm{NO}_{\mathrm{x}}$ formation. Many researchers have proved that increasing the cetane number through biodiesel blends would tend to reduce carbon monoxide and oxides of nitrogen. Cetane number $(\mathrm{CN})$ is a non-linear dimensionless parameter that affects ignition delay of diesel fuel upon injection into the combustion chamber. For hydrocarbon emissions, the effect of cetane number is insignificant.

\section{Experimental Setup}

Extraction of liquid biodiesel fuel from the non-edible oils is done by mechanical crushers known as oil expellers. Then the oil is treated for transesterification, purification and micro-emulsification to reduce fuel viscosity such that biodiesel would be suitable to be run in a diesel engine. As given in table.1, experiments are performed on a single cylinder, four stroke, constant speed, water cooled direct injection CI engine coupled to a rope brake dynamo meter with the selected biodiesels and their blends.

\section{Table 1. Details of the experimental setup for biodiesel emission test rig}

\section{Emissions formation in Single Cylinder CI Engine operated with biodiesel blends:}

Carbon monoxide is formed whenever carbon or substances containing carbon are burned with an insufficient air supply. Even though the amount of air required for combustion is theoretically sufficient, the reaction is not always complete. The combustion gases still contain some free oxygen and carbon monoxide. Biodiesel also contains free oxygen in its structure and percentage of oxygen increases with the percentage of biodiesel blend. The total hydrocarbon (THC) and carbon monoxide (CO) emissions tend to decrease because of the oxygen content and the enhanced cetane number of biodiesel fuel which helps for a more complete combustion (Agarwal AK., 2007). In this study, emissions were determined for a on a single cylinder $\mathrm{CI}$ engine, operated at different loads with selected biodiesels and their blends. As the blend percentage is increasing along with the operating load, $\mathrm{CO}$ and $\mathrm{HC}$ emissions were found increasing for biodiesels, but were less than those of when operated with diesel as the fuel. Tao Y, et.al observed that higher CN has been correlated with reduced $\mathrm{NO}_{\mathrm{x}}$ emissions (Tao Y). For the selected biodiesels and their blends, cetane numbers were evaluated and were used as inputs to the ANN model to predict the emissions.

\section{Artificial Neural Networks as a modelling tool for analyzing exhaust emissions:}

The combustion and emission formation is inherently non-linear and the conventional mathematical models fail to give solutions. Artificial Neural Networks is a real time diagnostic, modelling, control and optimization tool that has the ability to capture non-linearties of system variables. ANNs extract the required information directly from the data because of their unique learning capability. They are capable of learning from nonlinear data of a complex problem and can predict the desired values with high accuracy. An ANN usually consists of an input layer, some hidden layers, and an output layer. The input layer consists of all the input factors and information from the input layer is then processed in the course of one hidden layer, and a following output vector is computed in the output layer. Generally the hidden and the output layers have an activation function. The Sigmoid activation function applies a sigmoid transfer function to its input patterns, representing a good non-linear element to build the hidden layers of the neural network, such a layer is 
named as sigmoid layer. An important stage when accommodating a neural network is the training step, in which an input is introduced to the network together with the desired outputs, the weights and bias values are initially chosen randomly and the weights are adjusted, so that the network attempts to produce the desired output. When a satisfactory level of performance is reached (a performance goal value of 0.00001), the training stops, and the network uses these weights to make decisions. In the supervised learning, a neural network learns to resolve a problem simply by modifying its internal connections (biases of the Desired Output Layer and weights) by back-propagating the difference between the current output of the neural network and the desired response. The training algorithm searches for an optimal combination of network's biases or weights by moving a virtual point along a multidimensional error surface, until a good minimum is found, as represented by the figure.2 (represented in three dimensions for the sake of simplicity):

\section{Fig. 2 Multi dimensional representation of Error Propagation}

It adjusts the Layers' bias and the Synapses' weight, according to the gradient calculated by the teacher neuron and is back-propagated by the backward-transportation mechanism. Such an algorithm is known as feed forward back-propagation technique. Many optimization searching techniques are available based on the method of calculating the gradient. In this work, Levenberg-Marquardt Optimization algorithm is used for training and testing the data patterns. This algorithm is fastest method for training the moderate-sized feed forward neural networks up to several hundred weights.

The Levenberg-Marquardt algorithm uses the following approximation given in (1) to the Hessian matrix in finding out the gradient (MATLAB 6.0):

$\mathrm{X}_{\mathrm{k}+1}=\mathrm{x}_{\mathrm{k}}-\left[\mathrm{J}^{\mathrm{T}} \mathrm{J}+\mu \mathrm{I}\right]^{-1} \mathrm{~J}^{\mathrm{T}} \mathrm{e}$

Where $\mathrm{J}$ is the Hessian Matrix that contains first derivatives of the network errors with respect o the weights and biases, $\mu$ is the scalar and e denotes the error computed in the iterative process.

The above training algorithm known as trainlm and is implemented in Neural Network Toolbox of MATLAB 7.0. This algorithm uses the following parameters to work: the learning rate, that represents the 'speed' of the virtual point along the error surface represented by the grid in the figure, and the momentum, that represents the 'inertia' of that point.

There are 100 data patterns available from the experimental data pertaining to diesel engine runs with the pure diesel and biodiesel blends. $33 \%$ of the total data patterns have been used for validation and testing. All the input and target values were normalized to fall in the range of $[0,1]$. Neurons in the input and output layers have no transfer function and a sigmoid transfer function have been used for the neurons in hidden layers. The number of hidden layers is increasing based on the complexity of the problem and the extent of nonlinear relationship between inputs and target values. Output values during testing phase for the third new fuel and its blends, best architecture is found out to be 5-12-9-6-3 with 3 hidden layers and with a goal of 0.00001 which was reached in 473 training epochs. The predictions obtained with several architectures have been analyzed for Levenberg-Marquardt algorithm and the network architecture shown in fig. 3 had given high regression coefficients during the evaluation process of the neural network. Aim was to deduce the smallest and simplest neural network that works on faster optimization technique giving rise to minimization of the error within the least possible epochs.

Errors during learning and testing stages described as RMSE, $\mathrm{R}^{2}$ and mean average percentage error (MAPE) are given below:

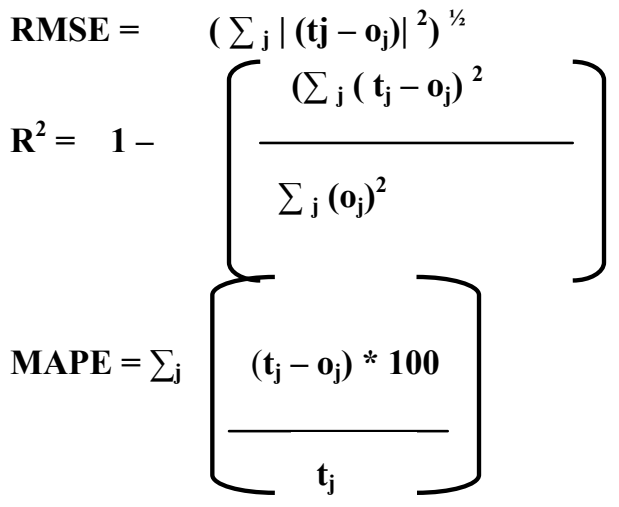

Where $\mathbf{t}_{\mathbf{j}}$ is target value and $\mathbf{o}_{\mathbf{j}}$ is output value.

Fig.3 Artificial Neural Network with inputs, outputs and hidden neurons

\section{Results and Discussions:}

The experimental investigation was carried out for different blends of Pongamia, Neem and Jatropha methyl esters 
(biodiesel), the emissions were evaluated and compared with diesel. This paper gives the result of ANN based predictions of emissions for the new biodiesels and its blends. A regression analysis is carried out to evaluate the performance of the adapted neural network model.

\subsection{Fuel Properties:}

Transesterification of the biodiesel oils has reduced the viscosity by greater extent and hence the biodiesel has been used in diesel engine test rig without making any modifications to the engine. Calorific value of the biodiesel blends decrease with the blend percentage of biodiesel but is comparable with diesel. Cetane number and density of the biodiesel blends are increasing with the increase in the percentage of biodiesel blend. Biodiesels and their blends have higher cetane numbers higher than diesel resulting in better ignition advance for the engine. Biodiesels contain more oxygen percentage by weight, more density than diesel and subsequently more amount of fuel can be injected resulting in reduced emissions. The influence of properties of the biodiesel blends on exhaust emissions along with the predicted values by ANN is shown in fig 4, 5, 6,7,8,9.

Fig. 4 Emissions vs. calorific values at No Load

Fig. 5 Emissions vs. calorific values at Rated Load

Fig. 6 Emissions vs. densities of biodiesel blends at No Load

Fig. 7 Emissions vs. densities of biodiesel blends at Rated Load

Fig. 8 Emissions vs. cetane numbers of biodiesel blends at No Load

Fig. 9 Emissions vs. cetane numbers of biodiesel blends at Rated Load

\subsection{Effect of Load with biodiesel blends percentage on emissions:}

At $75 \%$ of full load, $\mathrm{CO}$ and $\mathrm{HC}$ emissions of biodiesel blends are lower than those of diesel by nearly $60 \%$. But $\mathrm{NO}_{\mathrm{x}}$ emissions are higher in case of biodiesels due to increased temperature because of the higher cetane numbers giving rise to efficient combustion when the blend percentage is increasing. Effect of load on diesel engine exhaust emissions operated with biodiesel blends is shown in fig 10,11 and 12 .

Fig. 10 Actual vs. Predicted CO emissions varying under different loads

Fig. 11 Actual vs. Predicted HC emissions varying under different loads

Fig. 12 Actual vs. Predicted $\mathrm{NO}_{\mathrm{x}}$ emissions varying under different loads

\subsection{Neural Network Performance Parameters:}

Various training algorithms such as Gradient-Descent (traingdx), Conjugate-Gradient (traincgf) were used to obtain predictions for the desired emissions. During experience, it was found out that the optimum neural network architecture would be possible with Levenberg-Marquardt algorithm as shown below that has given improved regression coefficients. The goal for the training was set to 0.00001 and it took 473 epochs for achieving it as shown in table 2. A satisfactory performance was observed with the given number of neurons in the hidden layers for the selected neural network algorithm.

\section{Table 2. ANN parameters}

Fig. 13 RMSE during training process in MATLAB

\subsection{Performance evaluation of the developed ANN using Regression Analysis:}

Regression statistics output characterizes the goodness of the neural network model adapted as a whole. The regression analysis carried out to relate the actual and predicted data has shown that there is a high correlation between actual experimental values and predicted values. Regression Coefficient $(R)$ which indicates the amount of variation of actual and predicted values for $\mathrm{NO}_{\mathrm{x}}, \mathrm{CO}$ and $\mathrm{HC}$ was found out to be $0.99,0.95$ and 0.99 respectively. It implies that the model has succeeded in the prediction of diesel engine exhaust emissions. The lower value of $\mathrm{R}, \mathrm{R}^{2}$ for $\mathrm{CO}$ emissions may be due to incomplete combustion or any unseen variations in working conditions. Noise in the experimental data is captured by ANN and has given reduced regression value for CO. It was also observed that the curve fitting plot for each of the predicted emissions of Jatropha oil, most of the MAPE values are less than 15\%.

Figs 14 to Fig 16 are the residual and curve fitting graphs for all the predictions.

\section{Conclusion}

Following are the conclusions based on the experimental results and their simulation using artificial neural networks to predict the emission characteristics of a new biodiesel and its blends operated at different load conditions on a single cylinder diesel engine.

1) Biodiesel properties are similar to diesel fuel. Transesterification of biodiesel methyl esters helps not only in 
increasing the performance of the diesel engine but also in reducing $\mathrm{CO}$ and $\mathrm{HC}$ emissions.

2) Density, Calorific Value and Cetane Number are significant factors that influence the formation of exhaust emissions. Biodiesels and their blends give lower emissions compared to diesel. Higher the cetane number, higher will be the flame formation and the operating temperatures which will have a direct effect on increase of $\mathrm{NO}_{\mathrm{x}}$ emissions. Similar trend is observed for emissions under increasing operating load on the engine.

3) In this work, optimum artificial neural network architecture is designed to model the complex behavior of diesel engine exhaust emissions operated with biodiesels. The model developed is based on the most efficient and faster computing design optimization technique- Levenberg-Marquardt (trainlm). The other training algorithms such as Gradient-Descent (traingdx), Conjugate-Gradient (traincgf) were found to be inferior to trainlm that was able to predict $\mathrm{CO}, \mathrm{HC}$ and $\mathrm{NO}_{\mathrm{x}}$ emissions for the new biodiesel and its blends with improved accuracy.

4) This research work has shown that, for analyzing complex problems of emission analysis of biodiesels and their blends, artificial neural network is suitable, adaptable and flexible computing tool that can be used for diagnostic purposes. There by, time consuming, tedious and costly experiments can be avoided.

\section{References}

Agarwal AK. (2007). Biofuels (alcohol and biodiesel) applications as fuels for internal combustion engines. Progr Energy Combust Sci 2007; 33:233-71.

Avinash Kumar Agarwal, (2007). Biofuels (alcohols and biodiesel) applications as fuels for internal combustion engines,Progress in Energy and Combustion Science 33 (2007) 233-271

Canakci M, Van Gerpen JH. (2003). Comparison of engine performance and emissions for petroleum diesel fuel, yellow-grease biodiesel and soybean-oil biodiesel. Trans ASAE 2003;46:937-44.

Cloin R. Ferguson, Allan T. Kirkpatrick - Internal combustion engines

D. Agarwal, L. Kumar, A.K. Agarwal, (2007). "Performance Evaluation of a Vegetable oil fuelled CI Engine". Renewable Energy, accepted 29th June 2007

Graboski MS, McCormick RL. (1998). Combustion of fat and vegetable-oil derived fuels in diesel engines. Prog Energy Combus Sci 1998;24:125-64.

J. Sola and J. Sevilla, (1997). "Importance of data normalization for the application of neural networks to complex industrial problems," IEEE Transactions on Nuclear Science, 1997, 44(3) 1464-1468.

J.B. Heywood. (1988). “Internal Combustion Engine Fundamentals”, McGrawHill, New York,1988.

Java Object Oriented Neural Engine, User Guide

MATLAB 6.0 User Guide and Product Help for Neural Network Tool Box.

Nwafor, O.M.I. (2004). Emission characteristics of Diesel engine operating on rapeseed methyl ester, Renewable Energy, Vol. 29, No. 1, pp. 119-129, 2004.

Ouenou- Gamo s., ouladsine M. and Rachid A. (1998). "Measurment and prediction of diesel engine exhaust emissions "ISA Transactions 37 (1998) 135- 140.

S.Ouenou Gamo, M. Ouladsine and A.Rachid. (1999). Diesel Engine Exhaust Emissions Modeling Using Artificial Neural Networks - (SAE 1999-01-1163)

Tao Y, Operation of a cummins N14 diesel on biodiesel: performance, emission and durability. National Biodiesel Board, Ortech Report No. 95-E11-B004524

Timothy P. Gardner,Scott S. Low, Thomas E. Kenney and Richard C. (2001). Belaire Evaluation of Some Alternative Diesel Fuels for Low Emissions and Improved Fuel Economy - Ford Research Laboratory - (SAE 2001-01-0149)

United Nations Conference on Trade and Development: An Assessment of the Biofuels Industry in India, by Joseph B. Gonsalves on 18 October 2006 
Table 1. Details of the experimental setup for biodiesel emission test rig

\begin{tabular}{ll}
\hline Engine Specifications & \\
\hline Model of engine & Kirloskar \\
Combustion chamber & Direct injection \\
Engine type & Single Cylinder, Water-cooled, \\
& four strokes and naturally aspirated \\
Bore x stroke & 80 X 110 mm \\
Compression ratio & $16.5: 1$ \\
Injector opening & 210 bar pressure \\
Maximum power & $38.8 \mathrm{~kW}$ at 4250 rpm \\
Exhaust gas analyzer & HORIBA-MEXA-324 B \\
& (CO and HC) \\
& MRU DELTA $1600 \mathrm{~L}\left(\mathrm{NO}_{\mathrm{x}}\right)$ \\
Cetane Tester & Koehler K-88600
\end{tabular}

Table 2. ANN Parameters

\begin{tabular}{|l|l|l|l|l|l|}
\hline Activation Function & $\begin{array}{l}\text { Training } \\
\text { Rule }\end{array}$ & $\begin{array}{l}\text { Hidden Layers \& } \\
\text { Neurons }\end{array}$ & $\begin{array}{l}\text { Training } \\
\text { Error }\end{array}$ & $\begin{array}{l}\text { Regression } \\
\text { Coefficient } \\
\text { (R ) }\end{array}$ & $\mathbf{R}^{\mathbf{2}}$ \\
\hline $\begin{array}{l}\text { Linear (Input Layer) } \\
\text { Sigmoid(Hidden layer) } \\
\text { Linear (Output Layer) }\end{array}$ & trainlm & $\begin{array}{l}3 \text { Hidden layers } \\
12-1 \text { st Hidden } \\
\text { layer Neurons } \\
\text { 9- 2nd Hidden layer } \\
\text { Neurons } \\
\text { 6- 3rd Hidden layer } \\
\text { Neurons }\end{array}$ & 0.00001 & $0.9507(\mathrm{CO})$ & $0.9039(\mathrm{CO})$ \\
& & $0.9956(\mathrm{HC})$ & $0.9914(\mathrm{HC})$ \\
& & & & & \\
\hline
\end{tabular}<smiles>[R]OC([R])=O</smiles>

Esters

Figure 1. Structure of alkyl group methyl ester 


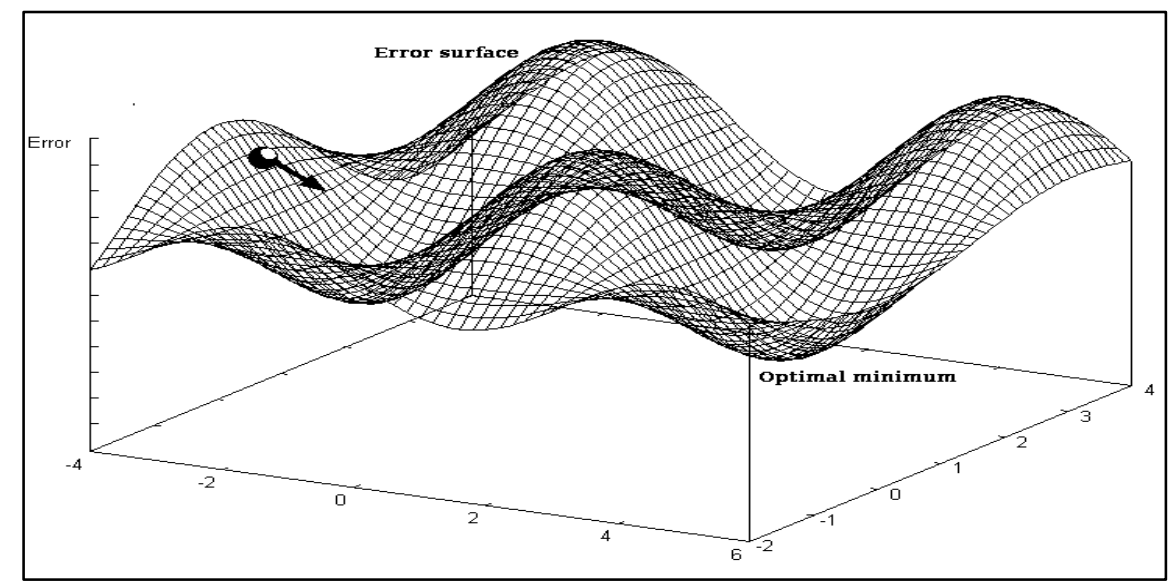

Figure 2. Multi dimensional representation of Error Propagation

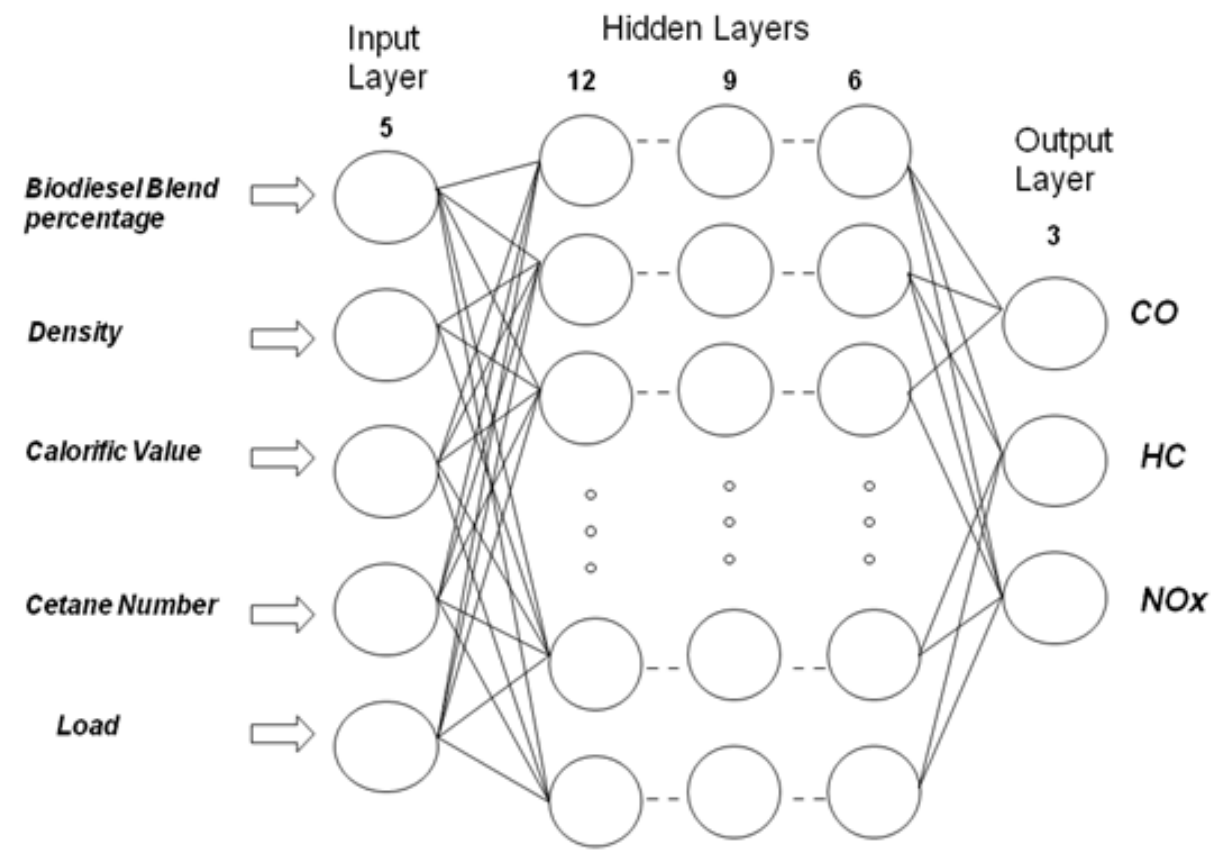

Figure 3. Artificial Neural Network with inputs, outputs and hidden neurons 


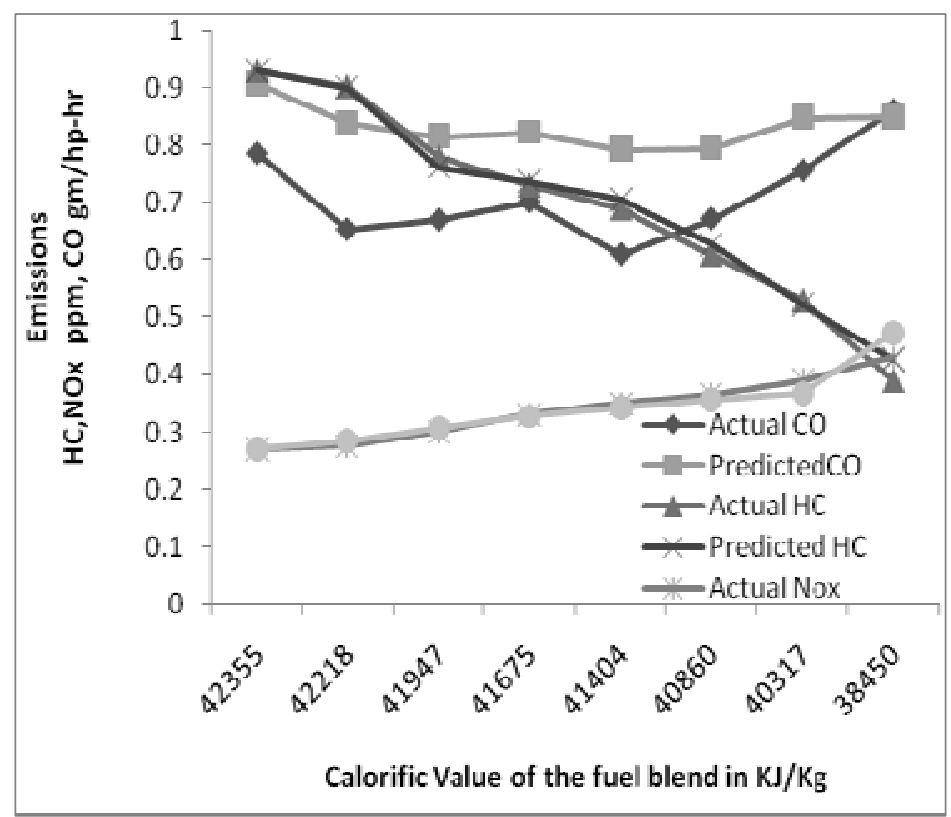

Figure 4. Emissions vs. calorific values at No Load

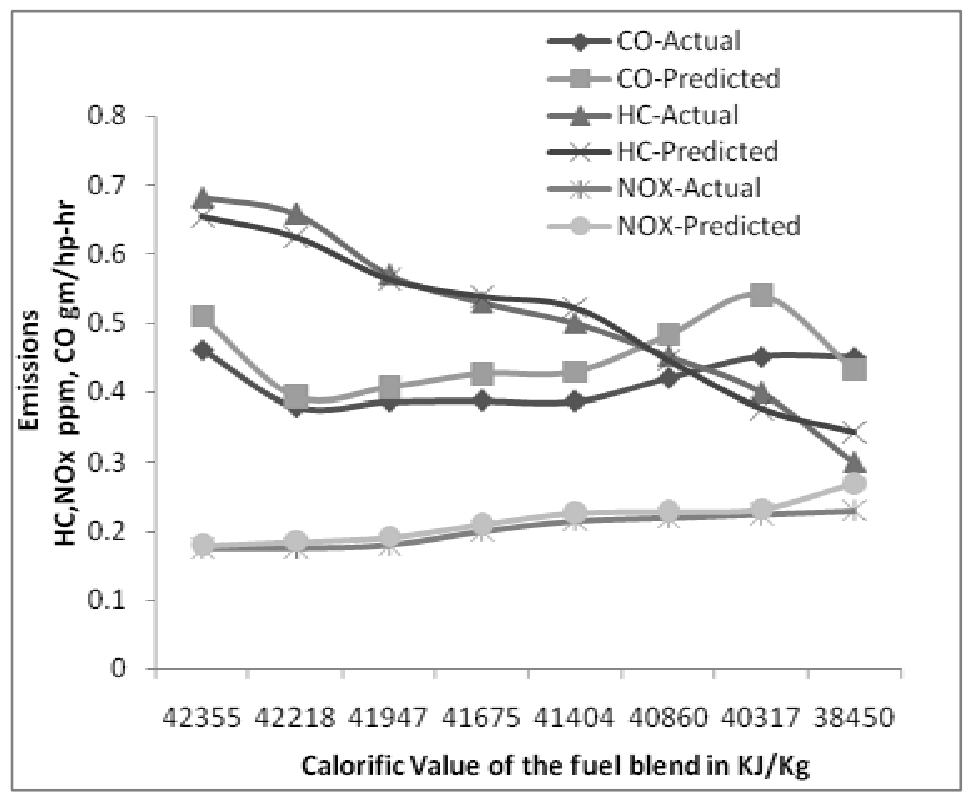

Figure 5. Emissions vs. calorific values at Rated Load 


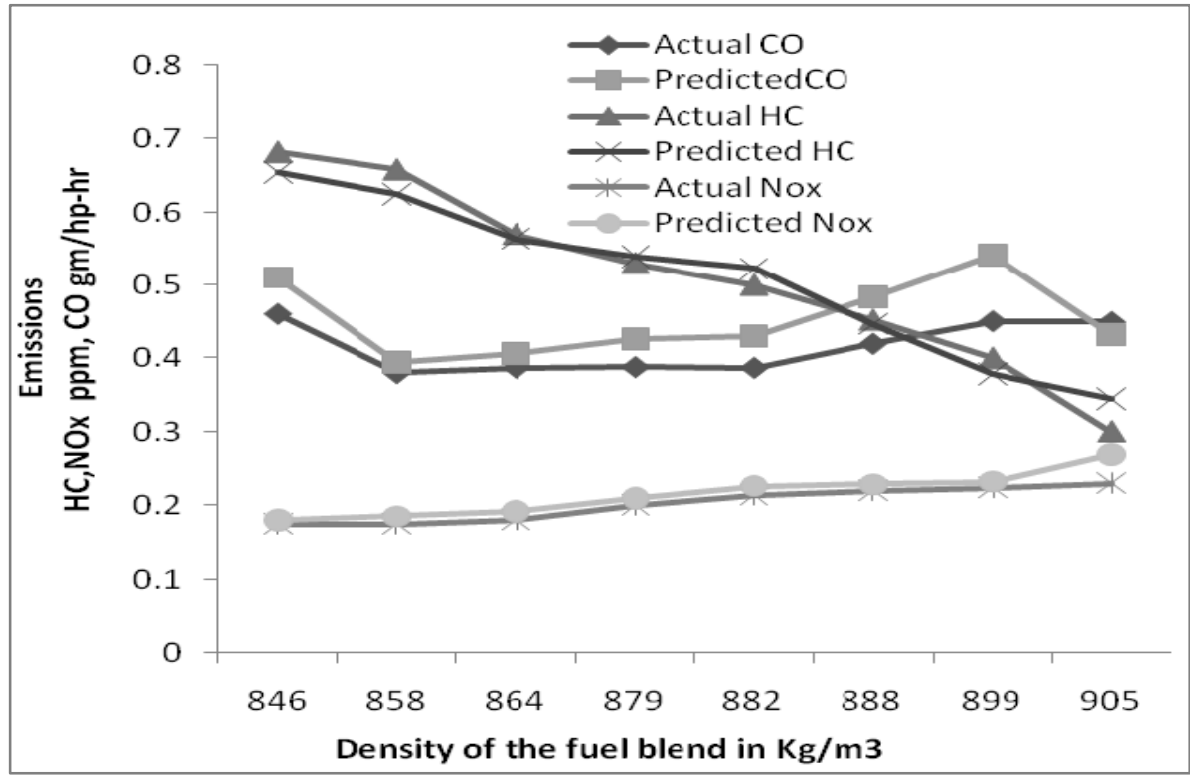

Figure 6. Emissions vs. density values at No Load

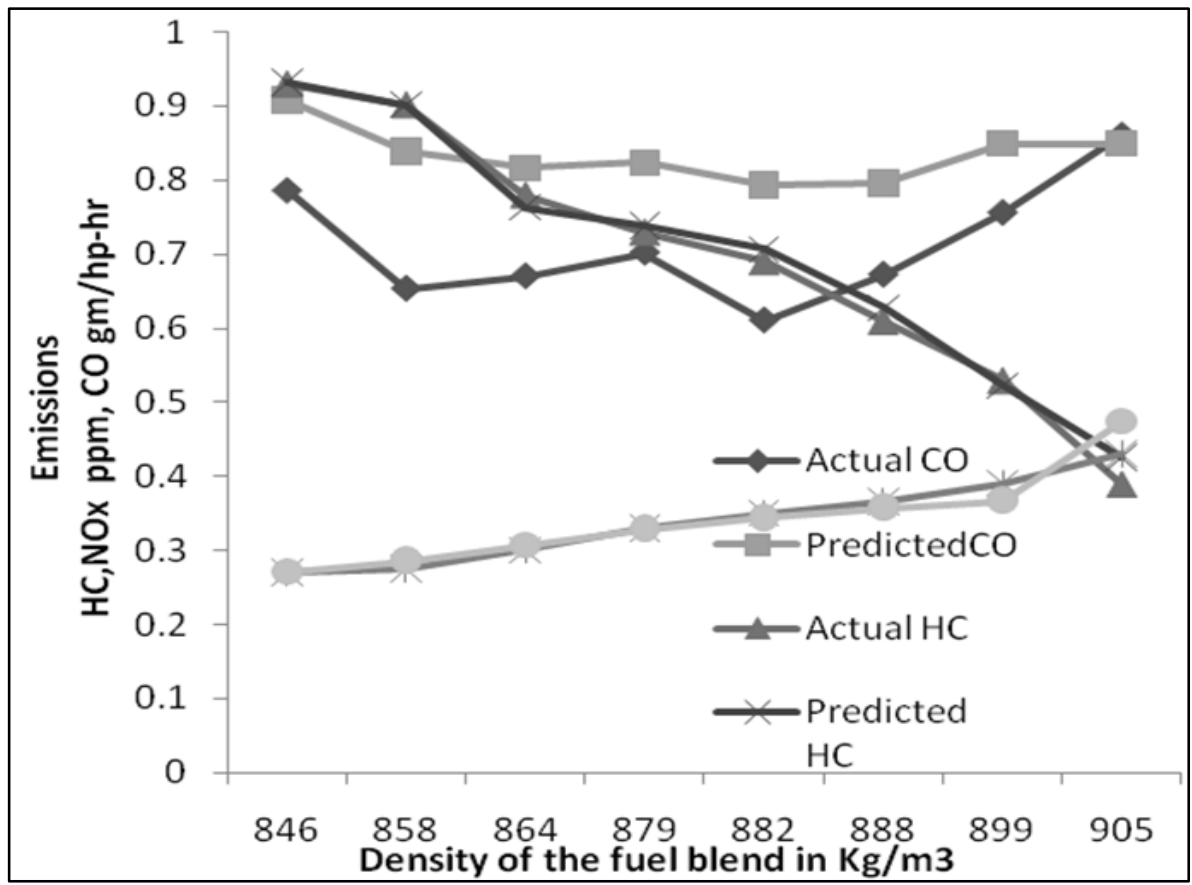

Figure 7. Emissions vs. density values at Rated Load 


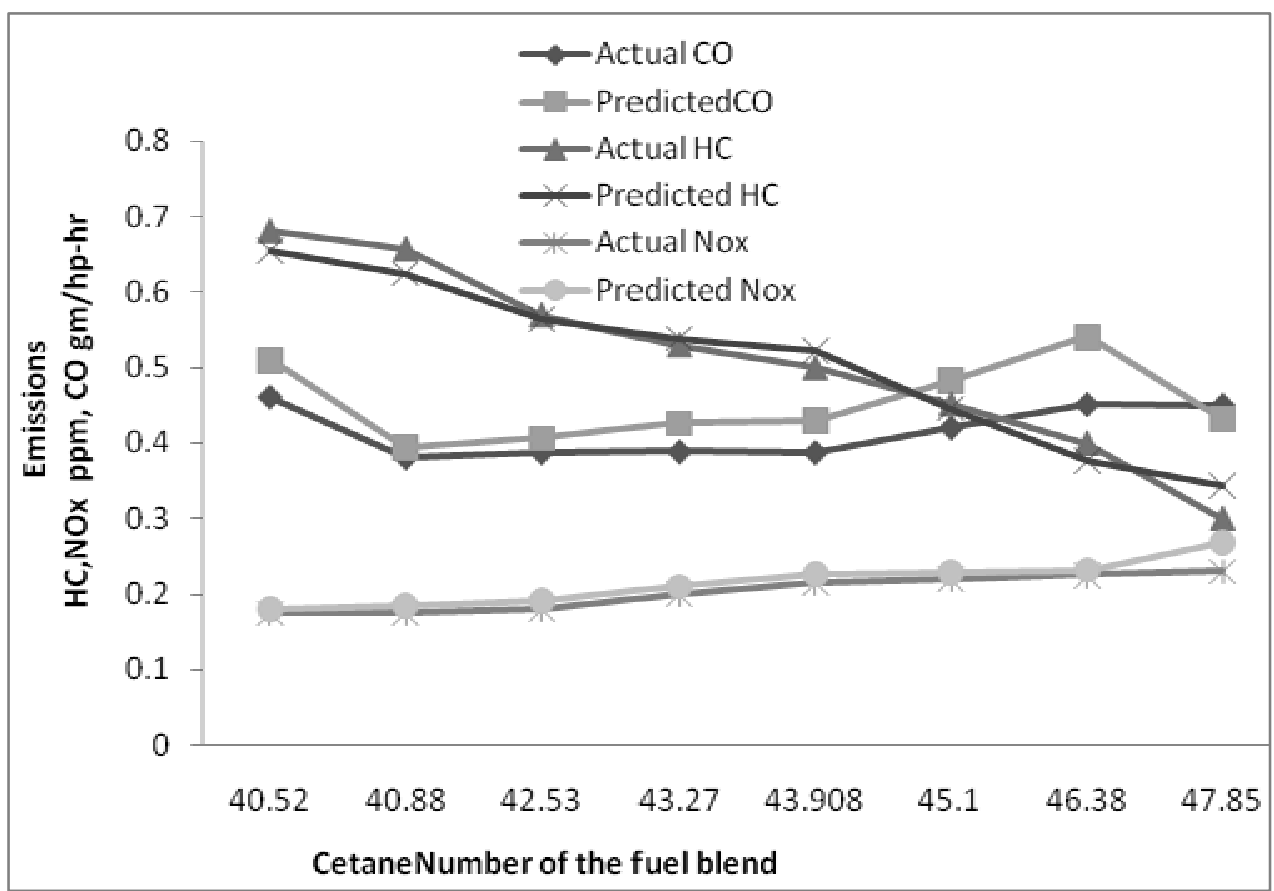

Figure 8. Emissions vs. cetane numbers of biodiesel blends at No Load

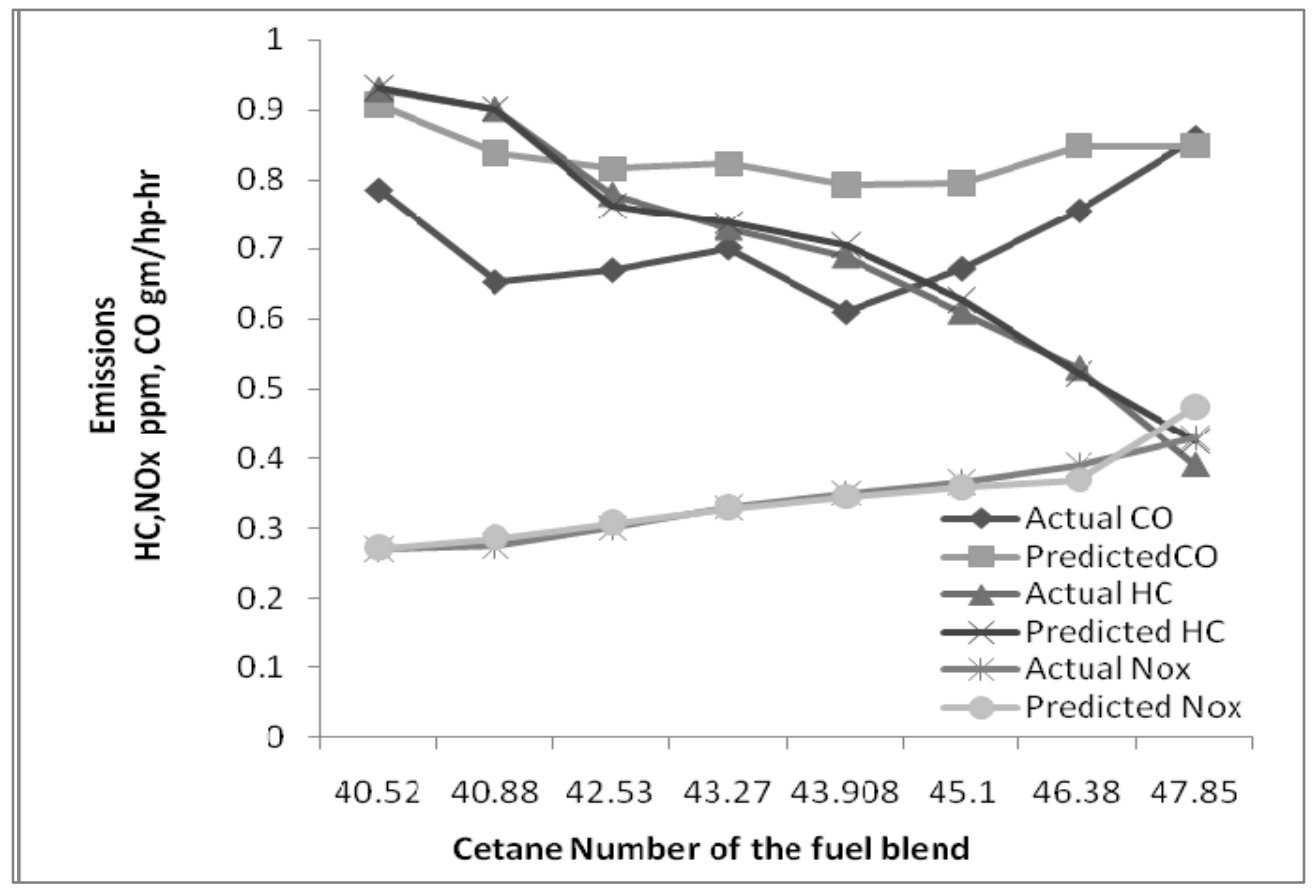

Figure 9. Emissions vs. cetane numbers of biodiesel blends at Rated Load 


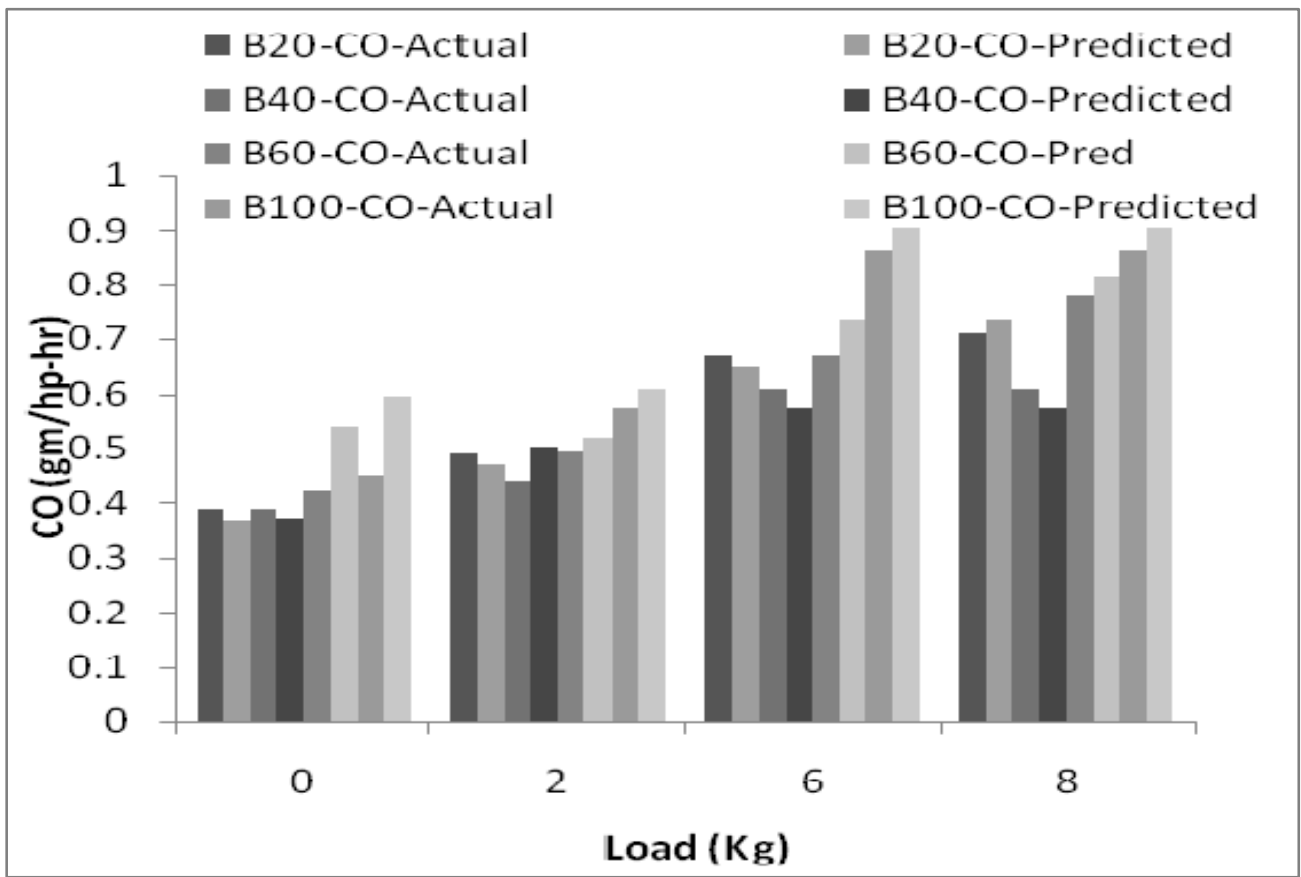

Figure 10. Actual vs. Predicted CO emissions under different loads

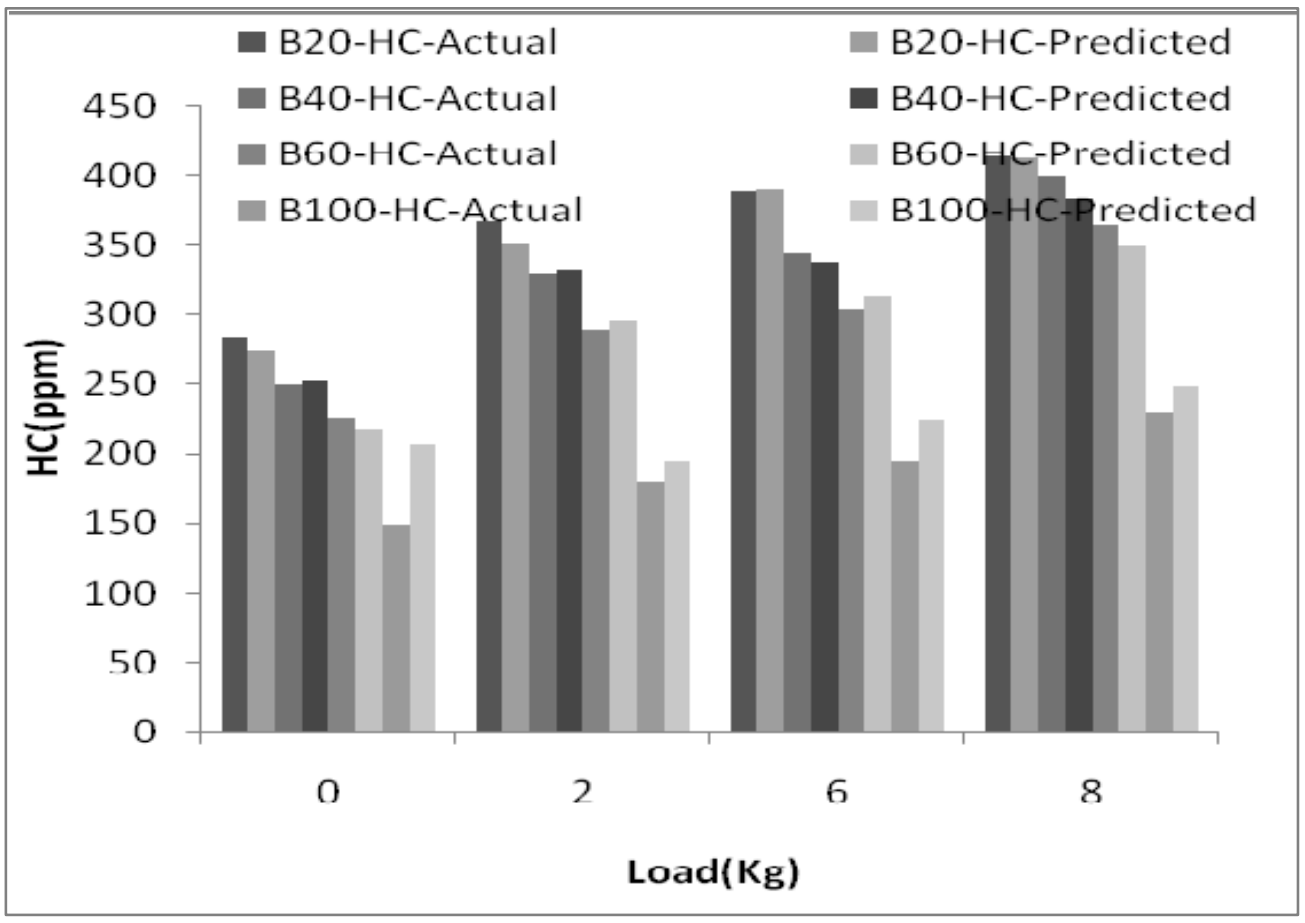

Figure 11. Actual vs. Predicted HC emissions varying under different loads 


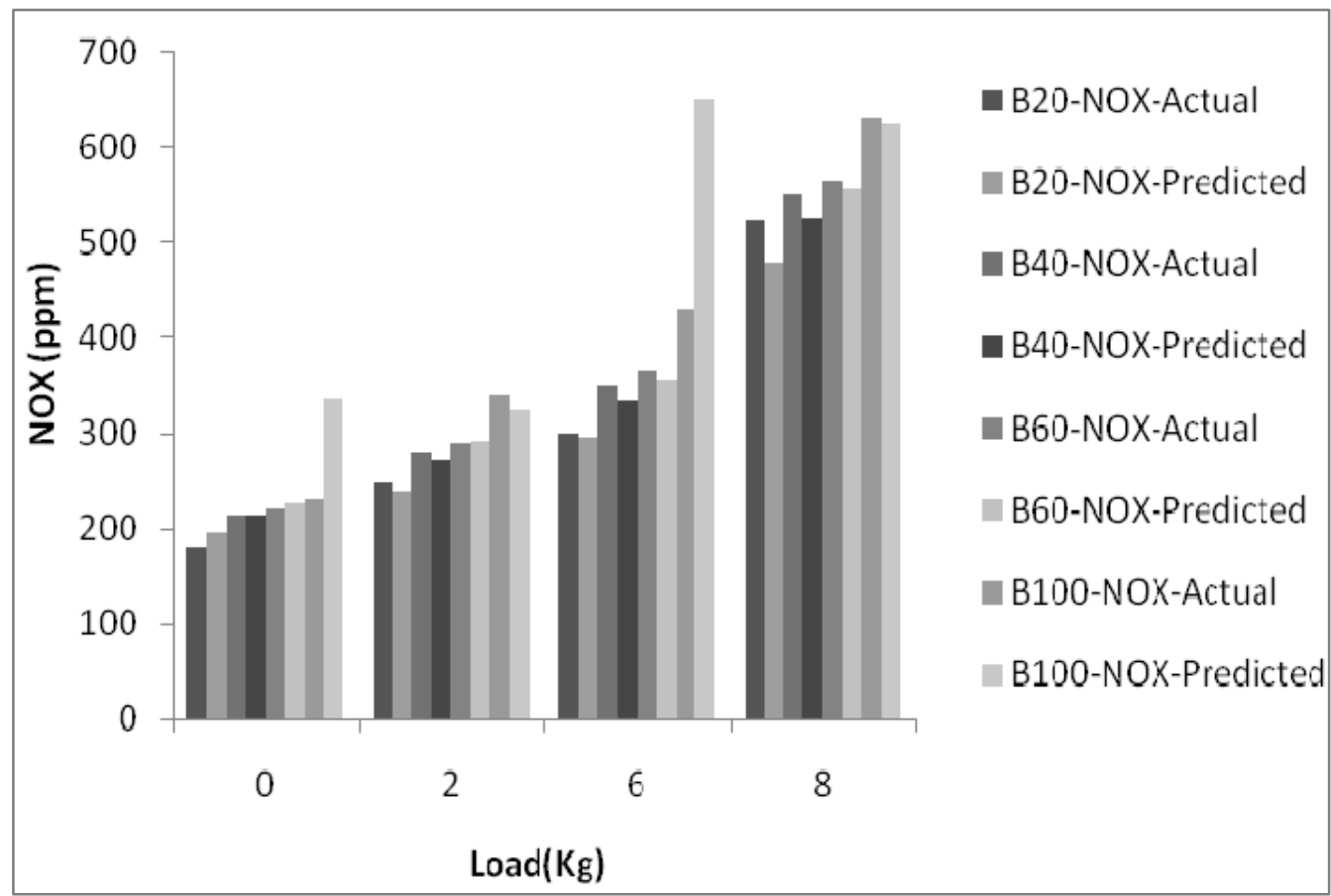

Figure 12. Actual vs. Predicted NOx emissions varying under different loads

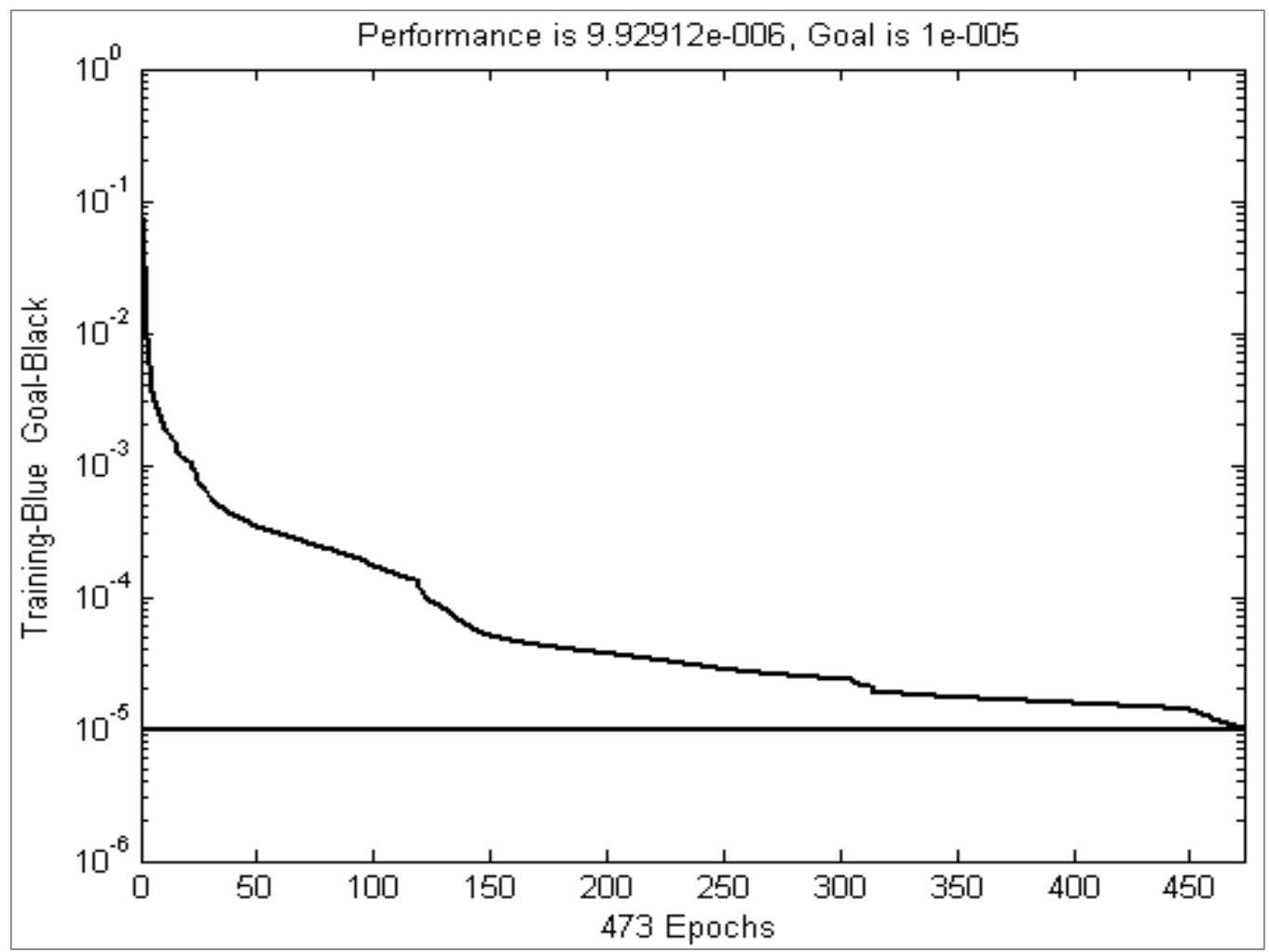

Figure 13. RMSE during training process in MATLAB 


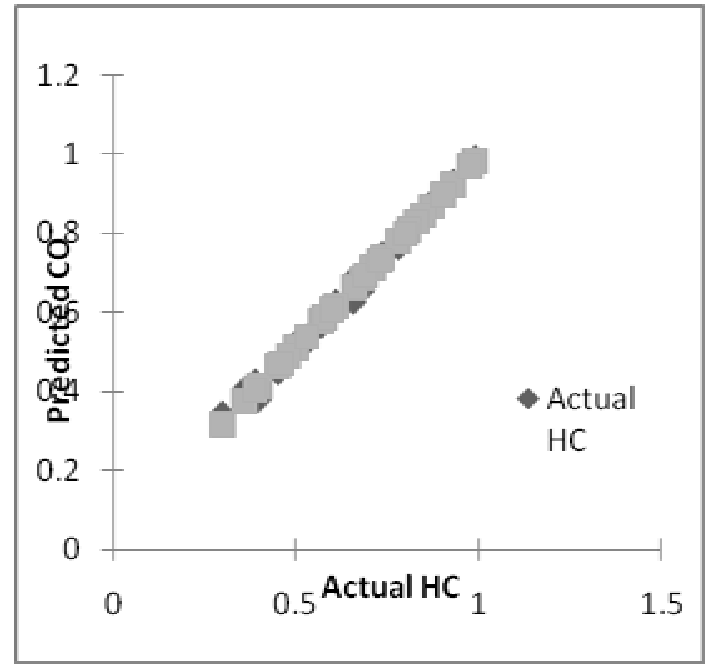

Figure 14. Curve fitting plot of $\mathrm{CO}$ predictions

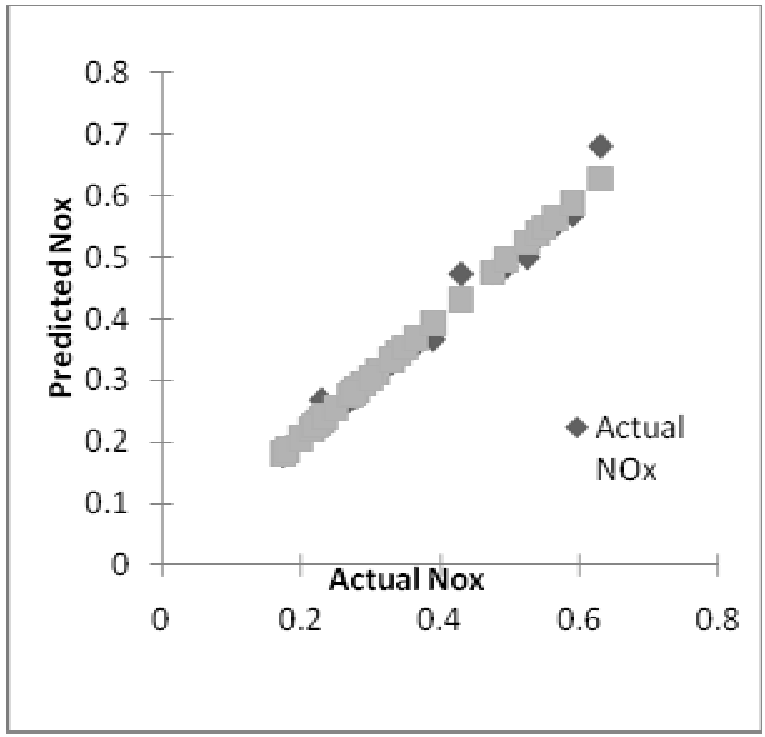

Figure 15. Curve fitting plot of $\mathrm{HC}$ predictions

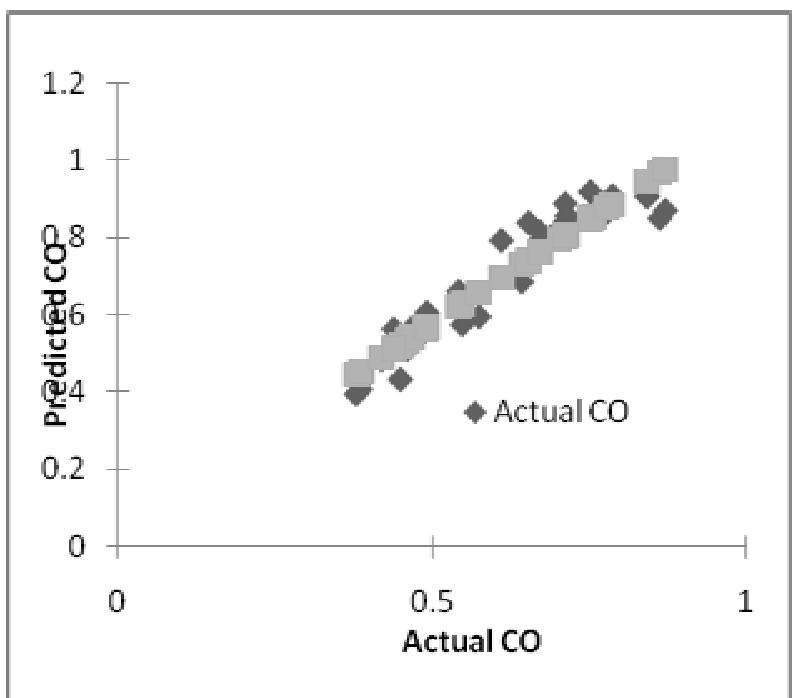

Figure 16. Curve fitting plot of NOx predictions 